\title{
A LEGISLAÇÃO DO ENSINO DE GRADUAÇÃO EM ENFERMAGEM
}

Taka Oguisso*

OGUISSO, T. - A legislação do ensino de graduação em enfermagem. Rev. Esc. Enf. USP, 10(2): 202-218, 1976.

E por via da legislação que se criam ou se extinguem não só direitos e deveres, mas as próprias instituições. Daí a importância de ccnhecê-la, mormente quando se trata da legislação da própria profissão. Além disso, o Código Civil e o Código Penal brasileiros dispõem que a ignorância ou a errada compreensão da lei não constituem alegações excusáveis quando se trata de cumprir a lei.

A autora analisa a evolução histórica da legislação no campo do ensino em nivel de graduação e sobre alguns aspectos dos cursos de pós-graduação em enfermagem. Descreve a situação atual do curso de enfermagem geral, de acordo com o Parecer do Conselho Federal de Educação n. ${ }^{\circ} 163 / 72$, e sugere a criação de habilitações também na área de Enfermagem Pediátrica e Psiquiátrica.

\section{INTRODUÇÃO}

Antigamente o ensino no Brasil era ministrado em nível primário, secundário ou médio e superior. $\mathrm{O}$ nível primário era feito em quatro anos e o médio era dividido em duas partes ou ciclos: o $1 .^{\circ}$ ciclo secundário, também chamado ginásio, em quatro anos, e o $2 .^{\circ}$ ciclo ou colegial em três anos.

Posteriormente, houve uma lei complementar à Constituição, chamada Lei de Diretrizes e Bases da Educação Nacional (Lei n. 4024, de 20 de dezembro de 1961) que, entre outras coisas, constituiu um órgão colegiado denominado Conselho Federal de Educação. A este Conselho, composto de vinte e quatro pessoas de notável saber e expe-

* Professor Assistente da disciplina Didática aplicada à Enfermagem da EEUSP. 
riência, em matéria de educação, nomeadas pelo Presidente da República, além de outras atribuições legais, competia estabelecer a duração e o currículo mínimo dos cursos de ensino superior.

Em 1968, foi promulgada a Reforma Universitária (Lei 5540 , de 28 de novembro de 1968), que se constituiu, basicamente, na extinção das cátedras, passando os Departamentos a ser a menor fração da estrutura universitária e na obediência ao princípio de vedar a duplicação de meios para fins idênticos.

A Lei ${ }^{\circ}$ 5540/68 alterou o dispositivo da Lei de Diretrizes e Bases, no que se refere a duração e currículo mínimo, e estabeleceu que o "Conselho Federal de Educação fixará o currículo mínimo e a duração mínima dos cursos superiores".

Novas alterações ocorreram em 1971, quando foram substituídos outros capítulos da Lei de Diretrizes e Bases, na parte referente ao ensino primário e médio, pela Lei.$^{\circ} 5692$, de 11 de agosto de 1971 . Nesta nova Lei, modificações profundas foram introduzidas na escola brasileira, integrando-se o antigo ensino primário e ginasial em um único curso, chamado de $10^{\circ}$ grau, correspondente a uma escolarização de oito anos letivos. $O$ ensino de $10^{\circ}$ grau é sucedido pelo de $20^{\circ}$ grau, que corresponde a três anos letivos de estudos, como era o antigo ciclo colegial.

São, portanto, onze anos de preparação, no mínimo, que devem anteceder o início de estudos em nível universitário, ou de $3 .^{\circ}$ grau. Para ingresso em cursos nesse nível, exige-se do candidato a aprovação em provas do concurso vestibular da área de conhecimentos correspondente. Tais concursos são realizados unificadamente para as universidades e alguns estabelecimentos isolados, ou individualmente, em outros estabelecimentos isolados de ensino superior.

As vagas nos cursos de $3 .^{\circ}$ grau são poucas em relação ao número de candidatos que concluem o $2 .^{\circ}$ grau e se inscrevem nos concursos vestibulares. Daí a necessidade de provas rigorosas para seleção de poucos candidatos entre os muitos que se apresentam para ingressar nas universidades. Em geral, há uma proporção de uma vaga para cada cinco a dez candidatos, e, até mais, conforme o curso. Somente estudantes excepcionalmente bons conseguem, logo ao término do curso de 
$2 .^{\circ}$ grau, sem outro preparo, ingressar no curso de $3 .^{\circ}$ grau. Há, portanto, um grande desnível de preparo entre concluintes do $2 .^{\circ}$ e ingressantes no 3. grau. Este é preenchido por cursos especiais de preparação às provas vestibulares ou "cursinhos", geralmente de nível mais elevado que os cursos regulares de $2 .^{\circ}$ grau, e que são frequientados pela maioria dos candidatos aos cursos universitários, perfazendo, assim, doze anos de estudos pré-universitários.

Estas modificações sucessivas no ensino brasileiro trouxeram, como não poderia deixar de ser, profundas repercussões para a enfermagem, que abrangeram desde a afluência de candidatos até o processo de formação de enfermeiros.

De acordo com o Relatório da Comissão de Documentação e Estudos, da Associação Brasileira de Enfermagem, nas trinta e oito escolas de enfermagem existentes no País, prestaram concurso vestibular, em 1974, com opção para enfermagem, 11.855 candidatos, dos quais foram classificados 1.958 para 1.886 vagas existentes. Do total de classificados, porém, apenas 1.414 matricularam-se na $1 .^{\mathrm{a}}$ série dos cursos de enfermagem.

Um dos fatores que vêm contribuindo para essa afluência de candidatos aos cursos de enfermagem é, justamente, a unificação dos concursos vestibulares nas universidades, o que possibilitou aos jovens tomarem conhecimento de que a enfermagem é curso superior. Assim, as escolas de enfermagem vêm, praticamente, preenchendo a totalidade das vagas oferecidas.

Hoje, o curso de graduação em enfermagem, seja ele integrante de universidade, ou realizado em estabelecimento isolado, segue a mesma diretriz básica dos outros cursos universitários e encontra-se perfeitamente integrado no sistema educacional do País.

\section{RESENHA HISTORICA}

A situação atual da enfermagem é uma decorrência de fatores históricos, cujo conhecimento auxiliará a compreender e valorizar o trabalho desenvolvido pelos pioneiros da profissão no País. 
Algumas considerações sobre o passado constituem, portanto, ponto de partida indispensável para avaliar o esforço e a luta constantes que cercaram a promulgação de todos os diplomas legais de determinação de currículo mínimo de enfermagem, de regulamentação do exercício da profissão, ou de controle de classe pela própria classe. Sendo assim, evidentemente, esta parte do trabalho não é original e nem inédita. E um resumo compilado de diversos trabalhos de enfermeiras que testemunharam e acompanharam a evolução da enfermagem no Brasil; que sentiram e viveram as muitas dificuldades e sacrifícios enfrentados pela classe; que vibraram com as conquistas e vitórias alcançadas; por isso mesmo, estão deixando para a enfermagem um patrimônio de tradições e lutas históricas inolvidáveis.

Uma legislação de ensino de enfermagem que trace diretriz adequada para a formação de profissional, no padrão ajustado ao atendimento das necessidades do País, é condição para a eficiência dos serviços de saúde.

A primeira iniciativa oficial de criação de uma escola de enfermagem para formação de enfermeiros ocorreu em 1890, com o Decreto n. $^{\circ} 791$, de 27 de setembro de 1890 . O ensino era ministrado por médicos e o curso era de dois anos. Ao candidato era suficiente saber ler e escrever corretamente e conhecer aritmética elementar. Como se vê, não se aplicava ainda o "sistema Nightingale", embora este já existisse na Inglaterra desde 1860 e nos Estados Unidos desde 1873. Por isto, considera-se que a enfermagem no Brasil teve início, efetivamente, em 1923, com a criação da Escola de Enfermeiras do Departamento Nacional de Saúde Pública, atualmente Escola Ana Neri (Decreto 16.300, de 31 de dezembro de 1923).

Nessa ocasião, algumas enfermeiras educadoras norte-americanas, enviadas ao Brasil pela Fundação Rockefeller a pedido de Carlos Chagas, Diretor do Departamento Nacional de Saúde Pública, instalaram a referida Escola, reorganizaram alguns hospitais que serviriam de campo de estágio e criaram o serviço de enfermagem de saúde pública no citado Departamento, na cidade do Rio de Janeiro.

Essas educadoras enfermeiras procuraram transplantar para o Brasil o sistema de ensino norte-americano, em moldes modernos. Esse 
sistema consistia em direção e ensino de enfermagem pelas próprias enfermeiras. Para garantir a elevação do ensino, exigia-se das candidatas, conforme previa o Decreto $n .^{\circ} 16.300 / 23$, o diploma de escola normal, ou documento que provasse "instrução secundária bastante", ou ainda um exame preliminar perante comissão de três professoras, como condição para matrícula. Esse diploma de curso normal, equivalente ao curso secundário completo, possibilitava acesso às faculdades.

De 1923 até 1931, quando foi promulgado o Decreto $n .^{\circ}$ 20.109 , de 15 de junho de 1931, que dispunha sobre a regulamentação do exercício profissional de enfermagem, essas educadoras norte-americanas devem ter lutado bastante. Prova disso consta do preâmbulo do referido Decreto, que parece uma satisfação dada à Escola Ana Neri por tê-la excluído da Universidade, quando diz: . . "considerando que, devido à conveniência da organização sanitária, não convém transferir agora para a Universidade do Rio de Janeiro, a Escola de Enfermagem Ana Neri, anexa ao Departamento Nacional de Saúde Pública, apesar da mesma satisfazer aos bons padrões técnicos encontrados em universidades de outros países..."

O Decreto $n .^{\circ} 20.109 / 31$ trouxe grandes benefícios para o ensino de enfermagem, pois, colocou a Escola Ana Neri como padrão e impediu a proliferação de escolas fracas; as demais escolas, para serem equiparadas a esse padrão, deveriam satisfazer a determinados requisitos básicos, que consistiam em: direção da escola por enfermeira diplomada, ensino de disciplinas de enfermagem e supervisão da prática também por enfermeiras, dispor de hospital com as condiçōes estabelecidas para prática de enfermagem e obedecer às mesmas condições e critérios estipulados para a Escola padrão na parte referente à admissão de alunos, duração do curso e organização do programa. Seguindo o modelo norteamericano de escolas criadas em hospitais, que não prescindiam das alunas de enfermagem o ano inteiro, também nas escolas brasileiras as alunas de enfermagem eram obrigadas a um serviço diário de oito horas, com direito a dois meios dias de descanso semanal e a uma quinzena de férias anuais. Assim, embora em três anos calendários, o curso equivalia a cinco anos acadêmicos.

A Escola Ana Neri foi a primeira e única escola de enfermagem do Brasil, nesse padrão, durante um decênio. Tal fato pode 
ser uma decorrência de que a sociedade brasileira da época, segundo Alcântara (1963) "não possuia noções definidas nem sobre o significado e nem sobre a utilidade de uma escola de enfermagem". Enquanto, em outros países, a enfermagem moderna surgiu como decorrência da necessidade de melhorar o padrão de serviço hospitalar no Brasil, que lutava na ocasião contra epidemias, ela começou no campo da saúde pública, para dar continuidade à tarefa de educação sanitária iniciada nos Centros de Saúde.

Daí a incompreensão e as dificuldades que durante tantos anos acompanharam a evolução e a implantação do ensino de enfermagem nos moldes da Escola Ana Neri. Em 1931 foi negada a inclusão dessa Escola na Universidade do Rio de Janeiro, mas, em 1937, sem alteração nos requisitos de matrícula, ela foi incorporada como instituição complementar à mesma Universidade, deixando de fazer parte do Departamento Nacional de Saúde Pública. Posteriormente, em 1946, a Escola Ana Neri passou a integrar a Universidade do Brasil como estabelecimento de ensino, o que constituiu uma vitória de grande significado pelo fato de contribuir para firmar o "status" profissional da enfermeira.

Em 1933, foi criada a Escola de Enfermagem "Carlos Chagas", em Belo Horizonte, Minas Gerais, e, a partir de então, foram fundadas diversas outras em todo o Brasil, tendo sido equiparadas ao padrão da Escola Ana Neri, no período de 1933 a 1949, treze escolas de enfermagem. A partir de 1949 (Lei n. 775/49), as escolas de enfermagem passaram a ser reconhecidas por decreto do Presidente da República. Entre as escolas equiparadas ao padrão Ana Neri, no período c1tado, uma se destaca pela importância da influência que exerceu, e continua a exercer, na enfermagem brasileira. E a Escola de Enfermagem criada anexa à Faculdade de Medicina da Universidade de São Paulo, que foi fundada em 1942 e representou um marco de grande progresso e renovação na enfermagem. Pelo Decreto n. ${ }^{0} 42.809 / 63$, foi essa Escola desanexada da Faculdade de Medicina da Universidade e transformada em estabelecimento de ensino superior. O mesmo ocorreu, posteriormente, com todas as escolas de enfermagem do País, que se encontravam anexas a Faculdades de Medicina, não havendo hoje escola alguma em tal condição.

A promulgação da Lei 775, de 6 de agosto de 1949, foi outra grande conquista no terreno da sistematização do ensino de enfer- 
magem. Esta Lei ou a sua regulamentação fixaram requisitos mínimos, equivalente aos demais estabelecimentos de ensino superior, tais como: exigência do secundário completo dos candidatos à admissão (com prazo de sete anos para seu cumprimento), existência de congregação e uniformidade de currículo. Manteve os princípios existentes de que: o diretor da escola de enfermagem deveria ser enfermeiro; e que as disciplinas específicas de enfermagem deveriam ser ministradas por enfermeiras.

A existência do secundário completo dos candidatos à matrícula continha uma ressalva, pois, foi concedido um prazo de sete anos, durante o qual foi possibilitado o ingresso de portadores de certificado de conclusão do $10^{\circ}$ ciclo secundário. Este prazo deveria terminar em 1956, mas houve prorrogação e, por fim, expirou em 1961.

Uma escola, porém, passou a exigir, em 1957, o secundário completo, não se valendo da prorrogação concedida. Outras foram sucessivamente seguindo o exemplo. Assim, na data fatal que expirou o prazo, muitas escolas já exigiam o secundário completo como requisito para matrícula.

O ano de 1961 representou um marco para a enfermagem, pois, colocou-a efetiva e definitivamente no nivel superior, com a cessação do prazo legal que possibilitava ingresso nas escolas de enfermagem de concluintes de curso ginasial ou $10^{\circ}$ ciclo secundário. Foi também o ano da promulgação da Lei de Diretrizes e Bases da Educação Nacional.

De acordo com as atribuições conferidas por essa Lei, o Conselho Federal de Educação fixou, para os cursos de enfermagem, o currículo mínimo e a duração, no Parecer 271, de 4 de dezembro de 1962, estabelecendo o curso em três anos letivos. Possibilitava, porém, após conclusão dos três anos de enfermagem geral, um quarto ano optativo em Saúde Pública ou em obstetrícia. Entretanto, no ano seguinte, pelo Parecer n. ${ }^{\circ} 303 / 63$, o Conselho Federal de Educação, ao fixar o currículo mínimo para os cursos de obstetrícia, modificou a Resolução decorrente do Parecer 271/62, possibilitando mútua complementação dos dois programas: a enfermeira com mais um ano de estudos específicos na área de enfermagem obstétrica poderia receber o diploma de 
enfermeira obstétrica ou obstetriz; a obstetriz, com um ano de complementação na área de enfermagem, poderia receber o diploma de enfermeira.

A redução do curso, que tradicionalmente tinha a duração de cinco anos acadêmicos embora realizado em três anos calendários, provocou grande reação por parte das educadoras de enfermagem, que consideravam três anos acadêmicos insuficientes para a formação do enfermeiro.

Menos de três anos depois, o Ministério da Educação e Cultura, pela Portaria n. ${ }^{\circ} 159$, de 4 de junho de 1965, fixou, sob novos critérios, a duração dos cursos superiores. Assim, o de enfermagem geral deveria ser feito com duração de dois anos e meio a quatro anos, com carga horária de 2.430 horas. Essa Portaria estabeleceu que as horas correspondentes a estágios supervisionados, no que excedesse a um décimo do número de horas nela fixado para o curso, não poderiam ser computadas para os fins de integralização do tempo útil, isto é, o tempo mínimo necessário para execução do currículo fixado para o curso.

A aplicação dessa Portaria aos cursos de enfermagem, que eram eminentemente profissionalizantes numa época em que predominavam os currículos de erudição, seria extremamente difícil, considerando a obrigatoriedade de atingir a integralização do tempo útil estabelecido em 2.430 horas em três anos, o que seria de aproximadamente quatro horas por dia, se se computassem apenas as horas de ensino em sala de aula. A solução viável, apontada por PINHEIRO (1967), no III Congresso de Educação de Enfermagem, realizado em São Paulo, foi o aproveitamento das horas de estágio para completar o ensino feito em sala de aula e em anotar todas as horas do aluno gastas nesta atividade. Para esse fim, a mesma educadora recomendou que a escola contasse com docentes na proporção de um para oito alunos, para o ensino clínico.

O texto legal suscitou uma dúvida entre as educadoras de enfermagem, porque ao Conselho Federal de Educação competia a fixação da "duração e currículo mínimo". A interpretação dada a essa frase pela Consultoria Jurídica da Universidade de São Paulo, embora um pouco forçada, como bem reconhece PINHEIRO (1973), era a de duração mínima e currículo mínimo. 
Com base nessa ou outra interpretação semelhante, as escolas de enfermagem, inconformadas com a redução do curso, procuraram ampliar a sua duração. Entre elas, as duas da Universidade de São Paulo "pleitearam e obtiveram do Reitor, em 1966, Portaria determinando que o curso de enfermagem fosse de quatro anos, com opção, no 4. ${ }^{\circ}$ ano, entre Enfermagem Obstétrica e Enfermagem de Saúde Pública.

Finalmente, o ensino de enfermagem, em 1968, foi novamente atingido pelas alterações introduzidas pela Reforma Universitária. A Lei n. ${ }^{\circ}$ 5.540, de 28.11.68, que substituiu um capítulo inteiro da Lei de Diretrizes e Bases, no que se refere ao ensino superior, estabeleceu como competência do Conselho Federal de Educação, já agora com clareza meridiana, a fixação do currículo mínimo e da duração mínima dos cursos superiores.

Assim, finalmente, o currículo mínimo dos cursos de enfermagem foi aprovado em 1972, constituindo o Parecer n. ${ }^{\circ} 163 / 72$, que se tornou a Resolução n. ${ }^{\circ} 4$, de 25 de fevereiro de 1972. Esta é a norma legal vigente que rege o curso de enfermagem geral no Brasil.

Portanto, foram necessários quase quarenta anos (1923 a 1961) para concretizar as aspirações contidas no Decreto que criou a atual Escola Ana Neri, além de outro decênio (1961 a 1972) para afirmar e unificar o ensino de enfermagem com o de Obstetrícia, pois, a Reforma Universitária, com o princípio de "vedar a duplicação de meios para fins idênticos", acabou integrando os dois cursos de obstetrícia, existentes na época, aos cursos de enfermagem. Se as condições sócio-econômicas e culturais brasileiras explicam e justificam essa demora, seus reflexos são sentidos até hoje, pois, são poucas as enfermeiras com preparo adequado em docência e que satisfazem às exigências atuais do ensino superior.

A aparente despreocupação pode ser explicada, também pela legislação do exercício profissional de enfermagem (Lei n. ${ }^{\circ} 2.604 / 55$ ) que, paralelamente à legislação do ensino, dava à enfermeira, entre outras, prerrogativas de: direção de escolas de enfermagem e de auxiliares de enfermagem; participação do ensino nessas mesmas escolas. 
Apesar dessas prerrogativas legais, as próprias educadoras de enfermagem sentiam necessidade de aperfeiçoamento e estudos mais aprofundados.

A instalação de cursos de pós graduação, no Brasil, com a finalidade de promover aperfeiçoamento e preparo para o magistério superior, constituiu uma iniciativa pioneira que coube às enfermeiras.

Houve diversas tentativas de cursos para formação de professoras de enfermagem, entre elas a da Escola Ana Neri, em 1947, que funcionou pouco tempo. Em 1959, foram criados os cursos de pós graduação em administração aplicada à enfermagem e em pedagogia e didática aplicada à enfermagem, na Escola de Enfermagem da Universidade de São Paulo. A criação desses cursos foi possível graças ao pessoal docente dessa Escola preparado no estrangeiro. Posteriormente, foi o curso de administração aplicada à enfermagem desdobrado em: administração de serviço de enfermagem e administração de unidade de enfermagem e criado o de administração do ensino de enfermagem. Tais cursos funcionaram sem interrupção desde seu início em 1959 até serem suspensos em 1969, e foram frequientados por enfermeiras de, praticamente, todos os países da América Latina e até da Africa.

Apesar desta preocupação em preparar enfermeiras para a docência, não houve o mesmo empenho para formação de doutoras e livres docentes, exigência esta que não estava contida na Lei n. ${ }^{\circ} 775 / 49$. De acordo com a regulamentação da pós graduação feita pelo Parecer n..$^{\circ}$, de 11 de fevereiro de 1969, do Conselho Federal de Educação, para o ensino em curso deste nível passou a ser. exigido do candidato a professor o título de Doutor. Eis porque foram fechados os cursos de pós graduação, em 1969, na Escola de Enfermagem da Universidade de São Paulo: as professoras foram se preparar para o doutoramento. Até 1967, só havia uma enfermeira, no Brasil e na América Latina, com o título de Professora catedrática em enfermagem: a Dr." Glete de Alcântara, que defendera tese em 1963 e conquistara esse título. Em outras profissões, especialmente na área de saúde, não havia cursos regulares para formação de professores de ensino superior, porém, os profissionais, por meio de provas e defesa de tese, foram conquistando títulos de doutor e livre docente. Assim, as enfermeiras tinham preparo para a docência, mas não o título, e os demais tinham o título, mas não o preparo. 
Tendo as primeiras enfermeiras conquistado o título de doutor, foram reabertos os cursos de pós graduação, já em nível de Mestrado e dentro dos requisitos regulamentados. A Escola Ana Neri recomeçou-os em 1972, a de São Paulo em 1973, a de Ribeirão Preto e a da Universidade Federal de Santa Catarina em 1975.

Hoje, já existem mais de dez livres docentes em enfermagem e muitas outras que estão se preparando para alcançar esse título nas Universidades Federais, nos moldes anteriores à Reforma Universitária, possibilitado pela Lei n. $^{\circ} 5.802$, de 11 de setembro de 1972 . Além dessas, há ainda outra dezena de doutoras em enfermagem, título esse obtido na Universidade de São Paulo.

\section{SITUAÇÃO ATUAL}

A Resolução n..$^{4}$, do Conselho Federal de Educação, de 25 de fevereiro de 1972 , baseada no Parecer n. $163 / 72$, fixou a carga horária dos cursos de enfermagem geral, sem incluir habilitação em 2.500 horas, com duração mínima de três anos e máxima de cinco anos. Incluída a habilitação, o curso passa a ser de quatro a seis anos, com carga horária mínima de 3.000 horas.

O currículo mínimo do curso de graduação em enfermagem aprovado por essa Resolução compreende três partes sucessivas: pré-profissional, tronco profissional comum ou ciclo profissional e habilitaçōes opcionais em: Enfermagem Médico-Cirúrgica, Enfermagem Obstétrica ou Enfermagem de Saúde Pública (Anexo I).

O pré-profissional deverá ser feito no campus universitário, juntamente com os demais estudantes da mesma área de conhecimentos. Inclui disciplinas das seguintes matérias: Biologia, Ciências Morfológicas, Ciências Fisiológicas, Patologia, Ciências do Comportamento e Introdução à Saúde Pública.

O tronco profissional comum, ou ciclo profissional, abrange matérias de enfermagem: Introdução à Enfermagem, Enfermagem Médico-Cirúrgica, Enfermagem Materno-Infantil, Enfermagem Psiquiátrica, Enfermagem em Doenças Transmissíveis, Exercício da Enfermagem, Didática aplicada à Enfermagem e Administração aplicada à Enfermagem. 
O curso que leva à formação do enfermeiro, isto é, o ciclo pré-profissional mais o tronco profissional comum, tem uma carga horária de 2.500 horas, que representa o mínimo determinado, mínimo esse não plenamente satisfatório. O próprio Conselho Federal de Educação diz que os currículos mínimos poderão ser "enriquecidos de outras matérias a critério da Instituição". Assim, de um modo geral as escolas vêm proporcionando cursos de enfermagem geral com carga horária de 3.000 ou mais horas, ministrados em sete a oito semestres. Também para as habilitações; embora a Resolução referida exija carga horária de apenas 500 horas, as escolas vêm ministrando cerca de 1.000 ou mais horas, em dois semestres.

As três habilitações referidas constituem, ao nível de graduação, uma forma de preparação mais aprofundada para o exercício profissional, mas sem abranger o campo total do conhecimento em que se insere a especialidade. Realmente, a habilitação proporciona ao aluno maior oportunidade de amadurecimento pessoal e profissional.

A formação da enfermeira obstétrica ou obstetriz depende, portanto, de estudos básicos em enfermagem geral, com duração mínima de três anos e de mais um ano de estudos aprofundados em enfermagem obstétrica. Só assim a enfermeira estará legalmente habilitada para o exercício da obstetrícia.

A habilitação em Enfermagem Médico-Cirúrgica proporciona extensão de estudos na especialidade, incluindo administração de Centro Cirúrgico, Enfermagem em Pronto-Socorro, em Unidade de Recuperação e de Terapia Intensiva e Administração de serviços de enfermagem hospitalar. Com esses estudos, o enfermeiro habilitado deve estar capacitado a atuar no campo hospitalar, com maior segurança e eficiência do que um outro profissional sem a habilitação.

A habilitação em Enfermagem de Saúde Pública busca, através de estudos mais aprofundados da especialidade, oferecer ao aluno optante a possibilidade de trabalhar com eficiência em unidades sanitárias, centros de saúde e ambulatórios.

Além dessas três modalidades de habilitações opcionais, há possibilidade de uma quarta opção para o aluno: é a licenciatura, em enfermagem. 
A Resolução CFE n. ${ }^{\circ}$ //72 incluiu dispositivo legal, àquela época já existente, consubstanciado na Portaria MEC n. $.^{\circ} 13 / 69$, que permite ao enfermeiro que receber, em estudos regulares, a formação pedagógica prescrita para os cursos de licenciatura, o diploma de licenciado em enfermagem, dando-lhe o direito ao registro definitivo como professor de $10^{\circ}$ e $20^{\circ}$ graus.

A licenciatura plena constitui requisito mínimo necessário para o exercício do magistério ao nível de $10^{\circ}$ e $29^{\circ}$ graus, de acordo com o art. 30, da Lei n..$^{\circ}$.692/71, que fixa as Diretrizes e Bases de Educação para o ensino de $1 .^{\circ}$ e $2 .^{\circ}$ graus. Na Enfermagem, o ensino de $10^{\circ}$ e $2 .^{\circ}$ graus corresponde aos cursos de auxiliar e técnico em enfermagem.

Assim, o licenciado em enfermagem pode lecionar, em quaisquer escolas ou curșos desses níveis, disciplinas da área de saúde relacionadas com a Enfermagem, Higiene e Programas de Saúde.

Todavia, a Resolução n. $.^{\circ} 4 / 72$, que criou a habilitação em Enfermagem Médico-Cirúrgica, não possibilitou habilitações em Enfermagem Pediátrica e em Psiquiátrica, que são igualmente necessárias, pela especificidade dos problemas existentes nas respectivas áreas.

A assistência à criança, doente ou sadia, sempre constituiu prioridade em todos os programas de saúde dos órgãos oficiais. A criação de mais esta habilitação estimularia a formação de profissionais mais bem preparados, além de abrir para as alunas mais uma possibilidade de opção.

A assistência psiquiátrica também apresenta um caráter específico e inconfundível, que demanda preparo especializado e mais profundo. E inegável que se trata, também, de área onde a assistência de enfermagem é das mais carentes por falta de profissionais bem capacitados. MINZONI et al (1975) provam esta afirmativa num trabalho sobre "a assistência de enfermagem psiquiátrica no Estado de São Paulo", dizendo que "a população de enfermagem é composta em sua maioria $(86,59 \%)$ por pessoal não profissional. Existem apenas sete enfermeiras para 8.151 leitos $\mathrm{e}$ as auxiliares de enfermagem não são preparadas, durante seu curso escolar, para este tipo de trabalho". Considerando tratar-se do Estado de São Paulo, um dos mais bem aquinhoados na dis- 
tribuição dos recursos humanos profissionais, a situação torna-se particularmente grave. E por isto que, a enfermagem psiquiátrica mereceria ser incluída entre as habilitações em enfermagem.

\section{CONSIDERAÇÕES FINAIS}

$\mathrm{Na}$ verdade, o problema da legislação do ensino de enfermagem não pode ser analisado de forma isolada. E mister inseri-lo no contexto global da situação, estudando-o também com relação ao exercício, pois, ambos, ensino e exercício, caminham juntos e são mutuamente dependentes. Falhas no ensino, fatalmente repercutirão no exercício. Por isso, o ensino deve estar atento e sensível para adequar constantemente o programa às necessidades do exercício. E a legislação deve acompanhar "pari-passu" a evolução dinâmica deste processo, e constituir, realmente, a expressão da vontade comum.

O conhecimento da legislação de enfermagem deixou de ser um diletantismo para estudiosos e-especialistas. Estão aí os concursos públicos diversos, que vêm incluindo o tema legislação em seus programas. Reclamações trabalhistas têm surgido na Justiça do Trabalho, promovidas, principalmente, por atendentes pretendendo equiparação salarial aos auxiliares de enfermagem com base na Consolidação das Leis do Trabalho (C. L. T.), art. 461, que dispõe: "Sendo idêntica a função, a todo trabalho de igual valor, prestado ao mesmo empregador, na mesma localidade, corresponderá igual salário, sem distinção de sexo, nacionalidade ou idade". Seja por falta de pessoal ou de definição de funções, o fato é que houve caso de nosso conhecimento em que uma enfermeira, chamada a depor como testemunha, acabou confirmando não fazer distinção na distribuição de tarefas para o auxiliar de enfermagem e o atendente, no respectivo hospital.

Considerando que é por via da legislação que se criam ou se extinguem não só direitos e deveres, mas as próprias instituições, pode-se avaliar a sua importância e a necessidade de conhecê-la, tanto mais, quando se trata da legislação da própria profissão. Além do mais, diz o Código Civil Brasileiro que "ninguém se excusa de cumprir a lei, alegando que não a conhece", e o Código Penal (art. 16) ratifica esse princípio dispondo que "a ignorância ou a errada compreensão da lei não 
eximem da pena". Portanto, desconhecer a lei, não isenta pessoa alguma da responsabilidade.

A criação e instalação dos Conselhos Federal e Regionais de Enfermagem, pela Lei 5.905/73, está obrigando os enfermeiros a se familiarizarem com a legislação da sua profissão. Desta vez, a fiscalização do exercício profissional já referida na Lei $n .^{\circ} 2.604 / 55$ e o Decreto $n$. $50.387 / 61$, que ficara no papel, vai ser uma realidade, assim como as sanções.

Para consolidar a posição já alcançada pelos enfermeiros, é mister que se promova a melhoria das condições de trabalho e, também, dos níveis de remuneração que servirão de atrativos maiores para os jovens e futuros profissionais. E isto se fará por meio da legislação, adequada e ajustada às necessidades do ensino e do exercício da enfermagem. $\mathrm{E}$ os legisladores não poderão prescindir dos enfermeiros para a elaboração de uma norma legal de enfermagem nessas condições. Para prestar essa colaboração, mais e mais enfermeiros precisam conhecer a realidade da profissão no País, a própria legislação de enfermagem e as leis pertinentes.

OGUISSO, T - The undergraduate nursing education legislation Rev. Esc. Enf. USP, 10(2): 202-218, 1976.

Legislation founds and extinguishes not only rights and duties but the own institution. Therefore it is important to know the Law, even more, if it is the own professional legislation. Beyond this the Brazilian Civil Code and the Penal Code decree that ignorance or wrong understanding of Law are not excuse of no fulfillment of Law.

The author analyses the historical evolution of legislation in teaching area at undergraduate level and some aspects of the graduate ccurses in Nursing. She describes the present situation of th general Nursing course, in accordance to Governmental.Judgement 163/72 of Federal Council of Education which establishes habilitacion in MedicalSurgical, Obstetrical and Public Health Nursing. The author proposes establisment of habilitation also in Psychiatric and in Paediatric Nursing. 


\section{REFERENCIAS BIBLIOGRÁFICAS}

1. AlCANTARA, G. - A enfermagem moderna como categoria profissional: obstáculos à sua expansão na sociedade brasiletra. Ribeirão Preto, 1963. (Tese - Escola de Enfermagem de Ribeirão Preto).

2. ALCANTARA; G. - Enfermagem: pessoal e suas categorias funcionais, Rev. Bras. Enf., 11 (1): 81-92, mar. 1958.

3. DOURADO, H. G. - Legislação para o controle do exercício da enfermagem, An. Enf., 7 (2): 154-175, jun. 1954.

4. FORJAZ, M. V. - Resumo das origens e desenvolvimento das escolas de enfermagem no Brasil focalizado a interferência do pensamento católico. Rev. Bras. Enf., 11 (3): 315-329, set. 1959.

5. MEDEIROS, N. R. D. - Relatório da Comissão de Documentação e Estudos 1974/1975. Rev. Bras. Enf., 28 (3): 85-91, jul/set. 1975.

6. MINZONI, M. A. et al - A assistência de enfermagem psiquiátrica no Estado de São Paulo. Rev. Paul. Hosp., 28 (8): 338-330, ago. 1975.

7. PINHEIRO, M. R. - A enfermagem no Brasil è em São Paulo. Rev. Bras. Enf., 15. (5): 432-478, out. 1962.

8. PINHEIRO, M. R. - Aplicação do novo currículo mínimo ao curso de graduação da Escola de Enfermagem da USP, Rev. Bras. Enf., 26 (4 e 5): 293-308, jul/set. 1973.

9. RESENDE, M. A. - Ensino de enfermagem. Rev. Bras. Enf., 14 (2): 110-158, abr. 1961. 


\section{ANEXO I \\ Esquema dos currículos de enfermagem}

1) Parecer $271 / 62$

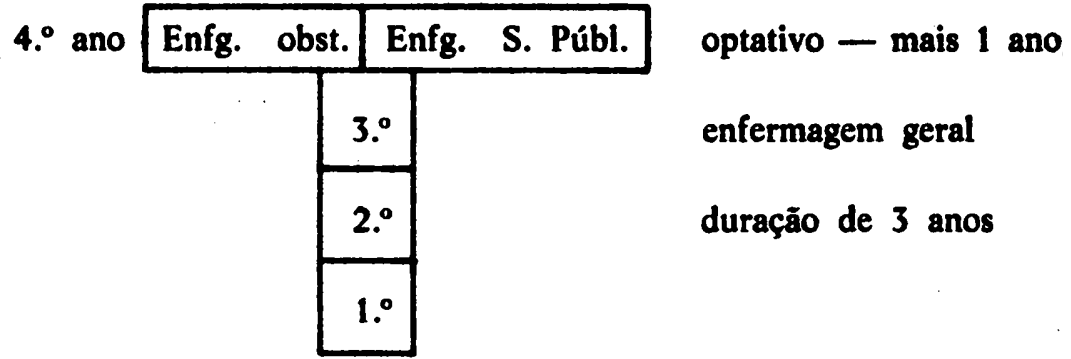

2) Parecer $303 / 63$

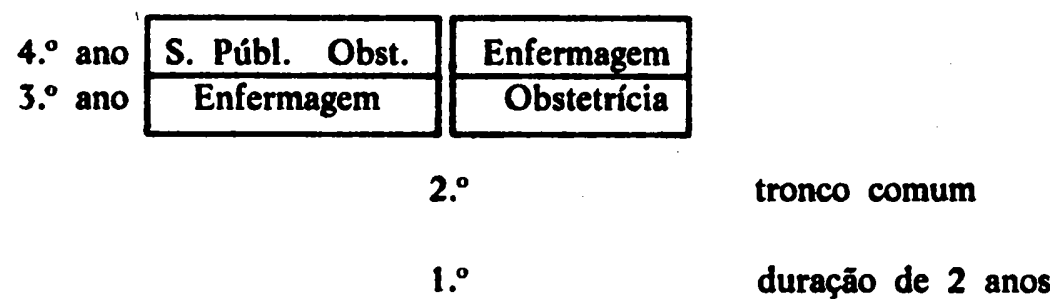

3) Parecer 163/72 (Resolução 4/72)

\begin{tabular}{|c|c|c|c|c|c|}
\hline $\begin{array}{l}\text { Habili- } \\
\text { tações }\end{array}$ & $\begin{array}{l}\text { Méd. } \\
\text { Enfg. } \\
\text { Cir. }\end{array}$ & Enfg. S. Públ. & Enfg. obst. & licenc. & $\begin{array}{l}\text { duração de } \\
\text { mais } 1 \text { a } 2 \\
\text { anos }\end{array}$ \\
\hline & $\frac{\text { Tr. }}{\text { pré }}$ & $\frac{\text { ofis. comum }}{\text { rofiss. }}$ & \multicolumn{3}{|c|}{$\begin{array}{l}\text { duração de } \\
3 \text { a } 5 \text { anos }\end{array}$} \\
\hline
\end{tabular}

